\title{
APPLICATION OF THE HOLE-DRILLING METHOD FOR MEASURING STRESS IN TIMBER STRUCTURAL ELEMENTS SUBJECTED TO COMPRESSION PERPENDICULAR TO THE FIBRES
}

\author{
M. CRESPO DE ANTONIO, D. LUENGAS-CARREÑO \& S. SÁNCHEZ-BEITIA \\ Higher Technical School of Architecture, University of the Basque Country (UPV/EHU), Spain.
}

\begin{abstract}
The hole-drilling method should be included among semi-destructive techniques (SDTs) in the in situ structural assessment. Many useful techniques are used in heritage for material assessment to measure density, stiffness or deterioration level in different materials, but there was not a technique used strictly for the structural analysis or for measuring stresses. Hole drilling is considered an SDT because drilling is needed to remove a part of the material in order to relax the existing stress. The relaxed strains are inferred due to the extraction of the material by drilling a hole of $18 \mathrm{~mm}$ in diameter and $16 \mathrm{~mm}$ in depth. The damage caused by that hole is minor and it does not affect the integrity of the supporting element nor its load-bearing capacity. Traditionally, the method was based on the ASTM E837 standard, only referred to residual stress in isotropic materials. These researchers have adapted the method for this natural orthotropic material: wood. Hole drilling has been adapted for a new material, a new application and a new scale. The importance of this new application lies in the possibility of measuring the current stress status derived from structural loads and other constructive actions in an existent building. This paper focuses on the measurement of a special situation in wood: compression perpendicular to the grain. The load-bearing strength of wood is very high in the fibre direction, but it decreases significantly in the perpendicular direction, causing large deformation due to the fibres being crushed. There is a specific piece supporting compression perpendicular to the grain whose Spanish name is 'zapata'. This structural element has been traditionally used in architecture. The tests in this paper were carried out at the laboratory, simulating the stress in 'zapatas' in real structures. The results obtained are the first approach to the application of the hole-drilling technique before applying it in real structures.
\end{abstract}

Keyword: ancient constructions, compliance tensor, compression perpendicular to the fibre, hole-drilling technique, on-site assessment, timber structures

\section{INTRODUCTION}

Wood is one of the most used construction materials in history, so it is usual to find it in historical buildings. Wood can suffer degradation due to its biological condition, added to other factors such as humidity changes and other kinds of alterations in the building, such as a change of use. For this reason, it is vital to know the real state of the structure before starting repair/reinforcement/restoration works. Nowadays, there are numerous techniques used to measure density, elasticity, moisture content and other physical properties, providing a current diagnosis of the material. Strength, stiffness and density properties are interrelated and they determine the strength level. In Spain, strength levels are standardized according to the UNE-EN 338 [1] depending on visual strength grading. Over time, wood properties or features can be modified by deteriorations, pathologies and disrepair. On-site assessment of the actual condition of the structure becomes fundamental to any decisions made relating to repairs and maintenance (Fig. 1).

A preliminary assessment is the first task to be carried out when a structure seems to be damaged. A technician should revise the historical and technical documents, should make a site inspection and the initial evaluation of the material status. Sometimes, urgent measures 


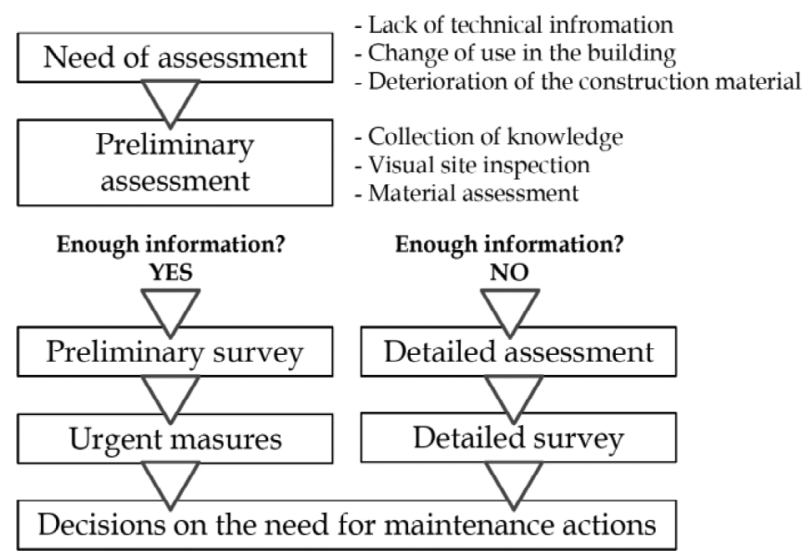

Figure 1: Assessment process in an existing timber structure.

need to be taken in order to guarantee security, even closing the building if necessary. Often, when the preliminary survey is not enough, the technician must make a more in-depth and detailed assessment. The inspection of the building and the detailed analysis of the material are made on site by using different techniques and portable equipment. Often, it is not possible to dismantle the structure or take a sample to bring to the laboratory, so this evaluation must be done on site. That is why developing in situ assessment techniques is very important. Additionally, the techniques should not damage the analysed element since the aim is to preserve the built heritage. Internationally [2-6], those techniques are divided into two main groups: Nondestructive techniques (NDTs) and semi-destructive techniques (SDTs).

There are many useful techniques for a detailed timber structure assessment. Some of them are based on stress waves, sounding, ground penetrating radar, radiography, resistance drilling, core drilling or hardness test [6]. They usually serve to measure some parameters related to density, elasticity and pathologies of wood. However, they are not useful to estimate the stress state in a wooden structural element in service.

Hole-drilling method is considered an SDT, due to the necessity of making a small hole on the surface of the element to relieve stresses and measure strains originated around it. This method has been applied on wood for the first time by the authors, obtaining successful results [7]. Although the application shown here is new, hole drilling is a well-known method. In 1930s, Josef Mathar presented the first device and some applications [8], but its use was limited to isotropic technological materials such as steel. Afterwards, ASTM E837 standard was published, ruling how to apply the technique [9]. However, this paper deals with a new application of the hole-drilling method. As wood is a natural anisotropic material, the ASTM E837 does not consider the application of hole drilling on it.

The first aim of this method was to measure the residual stress induced in materials during their manufacture. In real structures, stresses are derived from constructive loads, not from manufacture.

This work analyses the compression perpendicular to the grain, simulating the behaviour of 'zapata' structural elements (Fig. 2). In the Basque Country, as in other places, it is usual 

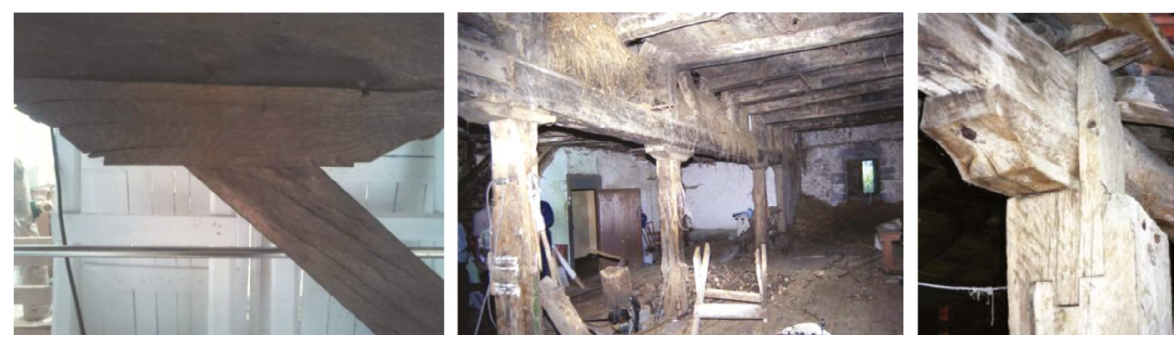

Figure 2: Examples of different 'zapatas' in existent structures of historical buildings in the Basque Country.

to find this element in many ancient buildings, where it is used for distributing loads from a beam to a pier or other element. In this paper, we discuss the hole-drilling technique which is used to measure stress in those specific structural elements that are subjected to high stress and large deformation. These tests could serve to validate the hole-drilling technique on the in situ assessment of structural timber elements.

\section{ADAPTATION OF THE HOLE-DRILLING TECHNIQUE}

The history of the hole-drilling technique started with the inception of Mathar in the 1930s [8]. In a few years, it became the most popular procedure to obtain the residual stresses in a wide range of materials. The technique has been developed and extended constantly since then.

The procedure involves making a hole, removing a part of the material and registering the strains originated around it. The relaxed strains are related to the original stress status, existing before making the hole, using the correct mathematical scheme. According to the procedure, first strains measurements carried out by Mathar were mechanical, but nowadays modern strain gauge rosettes and optical techniques have been developed for this task (Fig. 3). Similarly, the drilling tools are increasingly sophisticated and accurate in measuring stress in modern isotropic materials.

ASTM E837 standard establishes strain gauges position (three gauges rosette), hole diameter and depth of drilling for relating them with stress status, but it is only referred to isotropic materials [9]. There are many improved commercial devices to measure internal stress in technological isotropic materials (Fig. 3, right), but unfortunately, there is not one to measure
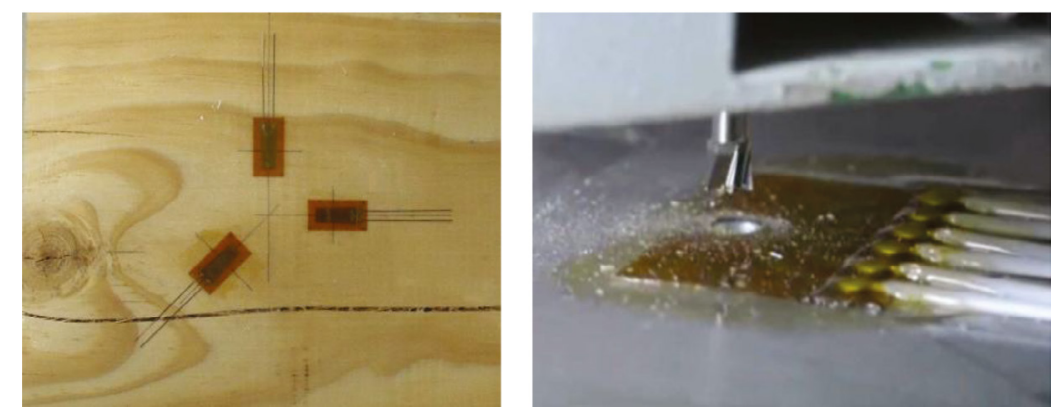

Figure 3: On the left, the individual strain gauges (HBM) forming a rosette, as developed by the authors, on a wood sample. On the right, a new technological device to be applied for drilling an isotropic material (Source: SINT Technology). 


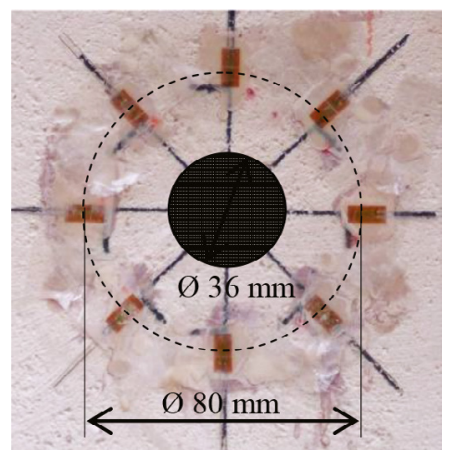

Figure 4: The eight-strain-gauge rosette glued to a stone pier.

structural stress yet. The rosette needs to be handmade using bigger single gauges. Due to the rosette and hole drilling having to be handmade, the scale should be increased to ease the process and to avoid errors. The authors of this paper were pioneers adapting the method for masonry structures in order to measure load stresses instead of manufacturing stresses [10-14]. There was no commercial rosette for this bigger scale and a rosette was designed using eight single strain gauges (Fig. 4).

The hole-drilling method for measuring load-bearing stresses in timber structures needs some additional changes in its mathematical scheme. The isotropic situation does not fit with timber elements. Schajer and Yang in 1994 [15] enriched the evolution of the method, publishing a new mathematical scheme for fibre-reinforced orthotropic composites, where a main elastic direction appeared in the direction of the fibres. The same scheme can be applied in the case of wood as it responds naturally to the same scheme with a main elastic direction, coinciding with the fibre's direction.

$$
\left(\begin{array}{lll}
c_{11} & 0 & c_{13} \\
c_{21} & c_{22} & c_{23} \\
c_{31} & 0 & c_{33}
\end{array}\right)\left(\begin{array}{l}
\sigma_{y} \\
\tau_{x y} \\
\sigma_{x}
\end{array}\right)=\sqrt{E_{x} E_{y}}\left(\begin{array}{l}
\varepsilon_{1} \\
\varepsilon_{2} \\
\varepsilon_{3}
\end{array}\right)
$$

In eqn (1) $c_{i j}$ are dimensionless constants of compliance, relative to each wood species and structural piece. The value of the constants $c_{12}$ and $c_{32}$ is zero when $X$ and $Y$ directions of the rosette coincide with the main elastic directions of the material. $\sigma_{y}, \tau_{x y}$ and $\sigma_{x}$ are the stresses in the $x-y$ plane. $\varepsilon_{1}, \varepsilon_{2}$ and $\varepsilon_{3}$ are the relaxed strains recorded by the rosette. $E_{x}$ and $E_{y}$ are the principal moduli of elasticity. The reference system shown in Fig. 5 has been applied in all the tests.

Some compression tests were done in order to validate the application of the hole-drilling method on wooden structural elements as was shown in STREMAH 2015 [7]. According to the recommendations of the standard, but also to the available boring tool (18 $\mathrm{mm})$ and commercial strain gauges size (10 $\mathrm{mm}$ in length) (Fig. 6), new dimensions for the experimental situation are $18 \mathrm{~mm}$ in hole diameter, $16 \mathrm{~mm}$ in depth of drill and $40 \mathrm{~mm}$ in rosette diameter (Fig. 7). 


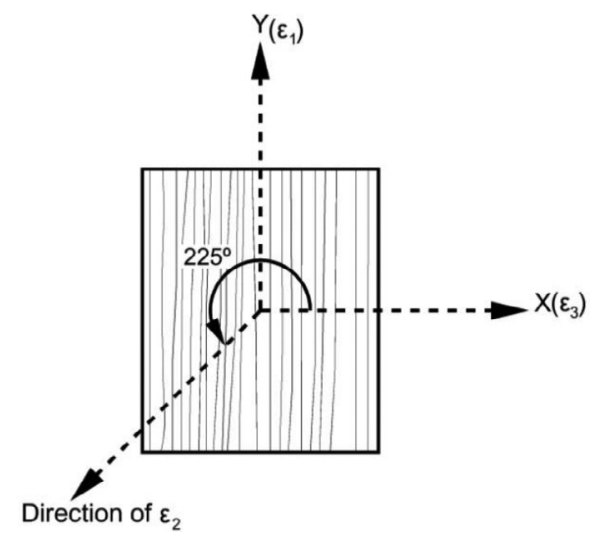

Figure 5: Plane reference system where direction of the grain coincides with the $y$ axis. The lines model the direction of the grain.

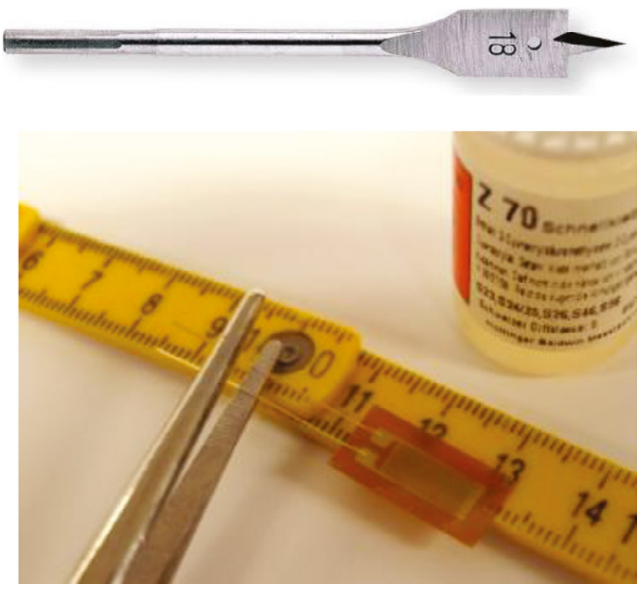

Figure 6: The boring tool (18 mm spade bit for wood) and one of the gauges used for the tests carried out on wooden samples.

In this case, there is no commercial device developed to be applied to these kind of structural elements. Therefore, according to the ASTM E837 standard's recommendations, the rosette is composed in situ by the researcher using three individual strain gauges as shown in Fig. 7.

The proportions between hole diameter, strain gauges size and the circumference diameter of the strain gauges disposal have been maintained according to the standard (ASTM E837) in order to ensure the stresses relaxation after the elimination of material by drilling, although the scale is increased. The material for the samples has been taken from a forest in the north of Spain and has been cut and tested without any previous treatment. All the tests were carried out in structural size pieces in order to get closer to the actual situation of an ancient structure. Knots and other defects affect the global resistance of the piece but they must be 

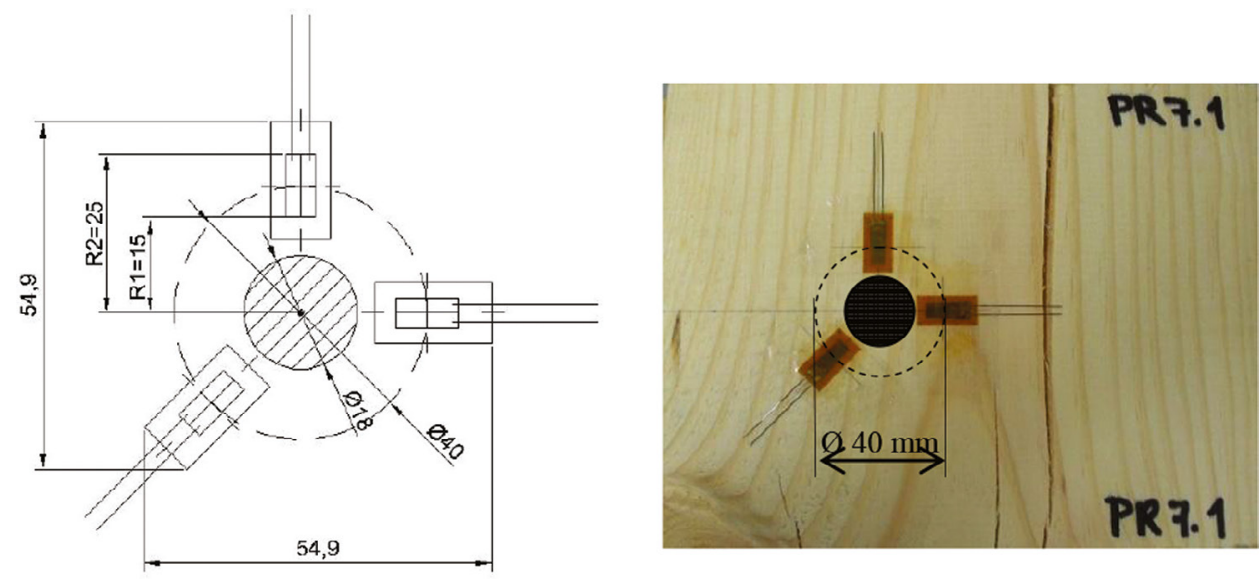

Figure 7: On the left, the device disposal scheme, measured in millimetres. On the right, a real sample with its rosette located avoiding a crack.

avoided when locating the rosette. When the rosette is glued onto the surface of the wood member, grain deviation, cracks and knots must be avoided. Registered strains around the hole could be wrong. Capturing the effect of defects or singularities of the whole sample is very interesting, but not if registering anomalous deformation due to the proximity of a fault. For example, a strain gauge should not be glued on a crack, or the drilling should not be performed where there is a knot. The technician must select the location of the rosette avoiding these singularities (Fig. 7, right).

The environmental conditions of the laboratory were $20^{\circ} \mathrm{C}$ and $50 \%$ of relative humidity. The material conditions reproduce the actual state of timber structures in existing buildings where this research is going to be continued in the following months. The axial and perpendicular compression tests allowed measuring values of the Young's elastic moduli during the loading process, relating stress and deformation in five load steps as was shown in STREMAH 2015.

\section{LABORATORY RESULTS}

Pinus radiata D. Don was the species selected for all the tests. It is a widely used wood in building timber structures in many zones of Europe. At the laboratory, three different tests were performed in order to complete the matrix of compliance under three types of compressive loads: compression parallel to the fibres, compression perpendicular to the fibres and tilted compression, on the special block (Fig. 8).

The values of the two Young's elastic moduli for this material and its structural size were measured in 20 blocks $(20 \mathrm{~cm} \times 20 \mathrm{~cm} \times 15 \mathrm{~cm})$. They were tested under compression stresses within the elastic zone, obtaining the following average values [7]:

$$
\begin{aligned}
E_{y} & =9442 \mathrm{MPa} \\
E_{x} & =621 \mathrm{MPa}
\end{aligned}
$$

At the laboratory, stresses were known and the relaxed strains were measured; therefore, the matrix of compliance was easily calculated using eqn (1). Finally the matrix of 

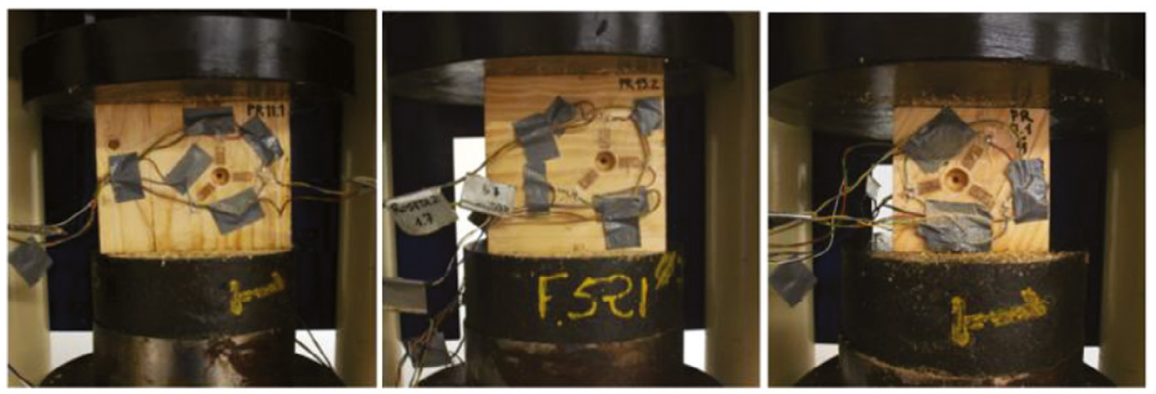

Figure 8: Real samples tested in the direction of the fibres (left), perpendicular-to-fibre direction (middle) and tilted to the vertical load direction (right).

compliance took the following value for Pinus radiata D. Don elements under compression $\operatorname{load}(2)[7]$ :

$$
C_{\text {PRcomp }}=\left(\begin{array}{ccr}
-0,789 & 0 & 0,075 \\
-0,419 & 2,110 & -1,030 \\
-0,092 & 0 & -2,359
\end{array}\right)
$$

\section{VERIFICATION TESTS}

The main objective of this paper is to measure stresses in compression perpendicular to the grain. That effect occurs in 'zapata' pieces. 'Zapata' means shoe in Spanish and it refers to a transitional horizontal element between a post and a beam, in order to avoid fibres flattening caused by punching (Fig. 9). Firstly, some verification tests were made at the laboratory, simulating stress in 'zapatas' in order to assure the applicability before testing a real structure.

'Zapatas' support compression perpendicular to the grain and wood is not as strong as it is under the compression parallel to the grain (Table 1). The Spanish standard UNE EN 338 [1] shows the values of different resistant classes of wood under different stresses. Pinus radiata D. Don structural elements are considered C22 in the coniferous classification [16].
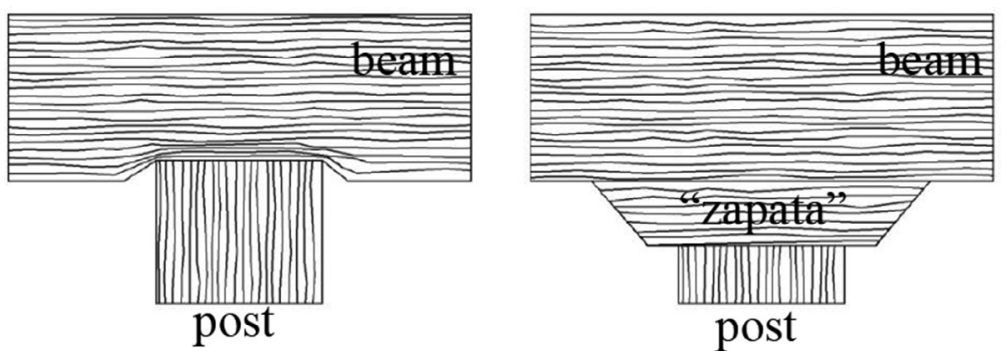

Figure 9: Details of joints between a post and a beam: On the left, a support without 'zapata', where the fibres of the beam are crushed, and on the right, a post supporting a beam, using a 'zapata' as a transition piece avoiding the crushing of the fibres of the beam. 
Table 1: Values of characteristic strength and elasticity according to C22 strength class [1].

\begin{tabular}{lcccccccc}
\hline & Bending & $\begin{array}{c}\text { Parallel Perpend. } \\
\text { tensile }\end{array}$ & tensile & $\begin{array}{c}\text { Parallel } \\
\text { comp. }\end{array}$ & $\begin{array}{c}\text { Perpend. Shear } \\
\text { comp. }\end{array}$ & $\begin{array}{c}\text { Parallel } \\
\text { elastic } \\
\text { modulus }\end{array}$ & $\begin{array}{c}\text { Perpend. elastic } \\
\text { modulus }\end{array}$ \\
\hline $\begin{array}{l}\text { C22 } \\
\text { Wood } \\
(\mathrm{MPa})\end{array}$ & 22 & 13 & 0.40 & 20 & 2.40 & 3.80 & 10,000 & 330 \\
\hline
\end{tabular}

Before testing a real 'zapata', eight blocks were tested under transversal compression only in order to check the data obtained for the first part of the laboratory tests. The eight blocks were approximately $20 \mathrm{~cm} \times 20 \mathrm{~cm}$ in cross section and $15 \mathrm{~cm}$ in height and the strain gauges were glued forming a rosette as shown in Fig. 10. They have been tested only under perpendicular compression simulating the stress in a 'zapata'. The checking tests were made at the laboratory, where the machine load was known. The comparison was made between stress derived from machine load and the stresses calculated by applying the correct mathematical scheme of the hole-drilling method. In eqn (3), $c_{\mathrm{ij}}$ the average values of the test performed for each constant of compliance are shown in matrix (2). The results in Table 2 compare the foreseeable stress from eqn (3) and the known stresses applied with machine loads.

$$
\left(\begin{array}{l}
\sigma_{y} \\
\tau_{x y} \\
\sigma_{x}
\end{array}\right)=\sqrt{E_{x} E_{y}}\left(\begin{array}{ccc}
c_{11} & 0 & c_{13} \\
c_{21} & c_{22} & c_{23} \\
c_{31} & 0 & c_{33}
\end{array}\right)\left(\begin{array}{l}
\varepsilon_{1} \\
\varepsilon_{2} \\
\varepsilon_{3}
\end{array}\right)
$$

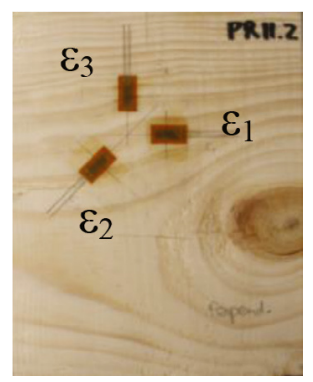

Figure 10: View of a real sample prepared for a verification test in compression perpendicular to the grain. 
Table 2: Summary of the results for the stresses obtained using the hole-drilling method in comparison with the applied stresses in laboratory, on eight blocks simulating a zapata's behaviour. 'ZBi' means Zapata-Block number 'i'.

\begin{tabular}{lcccccccc}
\hline & ZB1 & ZB2 & ZB3 & ZB4 & ZB5 & ZB6 & ZB7 & ZB8 \\
\hline $\begin{array}{l}\text { Applied stresses by } \\
\text { machine load (MPa) }\end{array}$ & -4.64 & -4.37 & -4.35 & -4.31 & -4.29 & -4.43 & -3.51 & -3.95 \\
$\begin{array}{l}\text { Stresses obtained by hole- } \\
\text { drilling method (MPa) }\end{array}$ & -5.15 & -3.75 & -4.35 & -4.77 & -2.85 & -4.30 & -2.55 & -3.03 \\
$\begin{array}{l}\text { Differences between } \\
\text { applied and obtained }\end{array}$ & 0.51 & 0.62 & 0 & 0.46 & 1.44 & 0.13 & 0.96 & 0.92 \\
$\begin{array}{l}\text { stresses (MPa) } \\
\text { Error }(\%)\end{array}$ & 11 & 14 & 0 & 11 & 34 & 3 & 27 & 23 \\
\hline
\end{tabular}

\section{DISCUSSION}

The objective of this research was the adaptation of the hole-drilling technique to be applied in timber structures. The first part of the research, presented in STREMAH 2015 [7], allowed results to be obtained for the moduli of elasticity and the compliance matrix for radiate pine structural elements. Both data allow a definition of the elastic behaviour of this type of wood. The procedure applied in STREMAH 2015 was repeated and completed with some new checking tests. The measurement of the real stresses on timber structures is vital in restoration works in order to enhance the conservation of historic structures and to promote the trust in wood as construction material. The results shown in this paper refer to the checking test made at the laboratory for perpendicular compressive loads simulating 'zapatas' in real structures. The tested material and the design of the samples reproduce the most common conditions existing in timber structures in many areas of Europe; that is why untreated samples were used for the checking tests (as was just taken from the forest without any special treatment) and the dimensions of the elements were large according to the real conditions (structural size, not small samples free of knots and fissures). All the values of the parameters involved in this research were specifically deduced in the previous laboratory work and no value has been taken from the bibliography, even the moduli of elasticity. Otherwise, the method is appropriate for 'zapata' pieces as the fibres were stretched from their original status under transversal compression and it is easier to measure the strains than in parallel compression (Fig. 11). Therefore, there are two main reasons for making the verification tests under perpendicular compression: the weakness of structural elements such as 'zapatas', which need to be assessed, and the clear strains in the fibres under transversal compression, where strain gauges would measure them properly.

Hole-drilling results were compared with real stresses for validation of the technique (Table 2). In the $62.5 \%$ of the cases, in five out of eight samples, the error was lower than $14 \%$, 


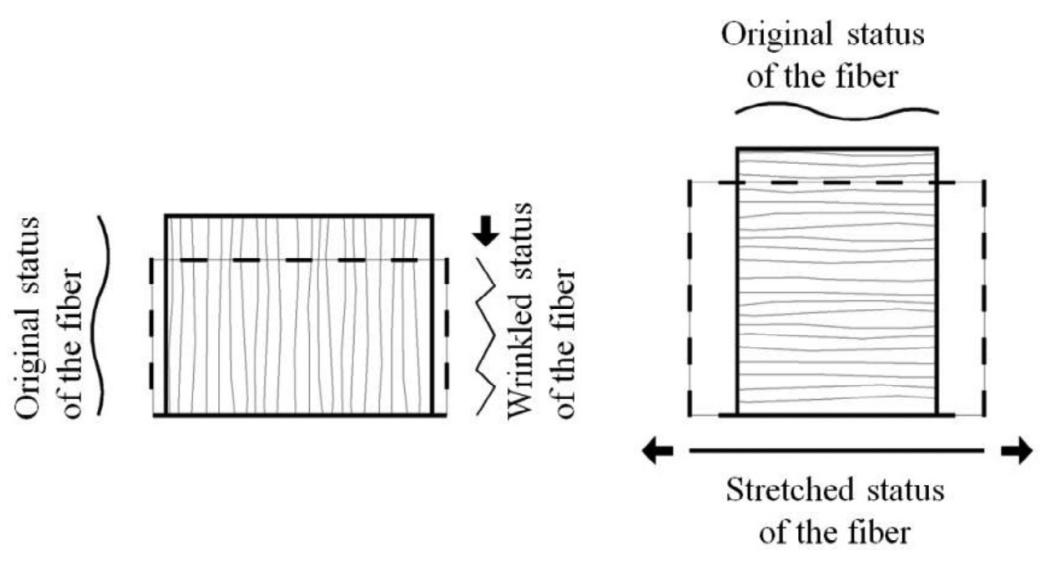

Figure 11: The same block in two different positions. On the left, the block is supporting parallel compression, where fibres are wrinkled from its original status. On the right, the block is supporting perpendicular compression, where fibres are stretched leading to clear strains.

being lower than $34 \%$ in the rest of the cases at study. It can be considered that the results obtained in the first part of the experimental work, to calculate the matrix of compliance and elastic moduli, were suitable, confirming those values. After these checking tests, the authors will perform tests in real structures, specifically in 'zapata' pieces, using the same procedure and the data obtained in this previous laboratory work.

\section{CONCLUSIONS}

We propose this novel procedure of the hole-drilling technique to be included among in situ assessment methods in the instrumental inspection of existing timber structures. It can be very useful for measuring structural stresses. It is the only useful method for structural analysis and to measure real stress status in linear wooden elements. Wood is not designed to bear loads in a perpendicular direction to its fibres, as it is not as strong as in the fibre direction. However, some structural elements or parts of elements, as shown in Fig. 8, support that kind of stress and are often prone to deformation. As shown in Fig. 11, fibres stretch and the strains measurements are clear. The first approach of the application of the technique in wooden elements was carried out on Pinus radiata D. Don, but many other species widely used in construction history should be studied at the laboratory in order to define more species' elastic moduli and elastic constants of compliance.

There is not a commercial device developed to be used in these types of elements and the rosette needs to be done in situ. The technician's work would be eased if a rosette was designed for this new application.

\section{REFERENCES}

[1] UNE-EN 338, Madera estructural. Clases resistentes/Structural Timber - Strength Classes. Spain: AENOR Standard (2010).

[2] Kasal, B. \& Anthony, R. W., Advances in in situ evaluation of timber structures. Progress in Structural Engineering and Materials, 6(2), 94-103 (2004). DOI: 10.1002/ pse. 170 . 
[3] Bucur, V., Nondestructive Characterization and Imaging of Wood. Germany: SpringerVerlag Berlin and Heidelberg GmbH \& Co. KG. (2003). ISBN: 9783540438403.

[4] Riggio, M., Anthony, R.W., Augelli, F., Kasal, B., Lechner, T., Muller, W. \& Tannert, T., In situ assessment of structural timber using non-destructive techniques. Materials and Structures, 47(5), 749-766 (2014). DOI: 10.3997/1873-0604.2010048.

[5] Tannert, T., Anthony, R.W., Kasal, B., Kloiber, M., Piazza, M., Riggio, M., ... Yamaguchi, N., In situ assessment of structural timber using semi-destructive techniques. Materials and Structures, 47(5), 767-785 (2014). DOI: 10.1057/jba.2008.4.

[6] Kasal, B. \& Tannert, T. In Situ Assessment of Structural Timber. Netherlands: Springer Science \& Business Media (2011). ISBN: 9789400705593.

[7] Crespo de Antonio, M., Luengas-Carreño, D. \& Sánchez-Beitia, S. Advances for the on-site determination of the stresses state in timber structures in service. WIT Transactions on the Built Environment, 153, 771-781 (2015), WIT Press. ISSN 1743-3509. DOI: $10.2495 /$ STR150641.

[8] Mathar, J., Determination of initial stresses by measuring the deformation around drilled holes. Transactions of the ASME, 56(4), 249-254 (1934).

[9] ASTM E837-01, Standard Test Method for Determining Residual Stresses by the HoleDrilling Strain-Gage Method (2001).

[10] Barrallo, J., Zulueta, A. \& Sánchez-Beitia, S., The Donostia method for the stress measurements in architectural heritage. Strain, 35(3), 107-112 (1999). DOI: 10.1111/j.14751305.1999.tb01141.x.

[11] Sánchez-Beitia, S., Stress analysis of the piers of the Tarazona Cathedral (ZaragozaSpain) by means of the hole-drilling technique. Construction and Building Materials, 22(5), 966-971 (2008). DOI: 10.1016/j.conbuildmat.2006.11.024.

[12] Sánchez-Beitia, S. \& Roca, P., Hole drilling technique for on-site stress measurements of masonry piers: Analysis of the Santa Maria del Mar Cathedral in Barcelona, Spain. Journal of Architectural Engineering, 20(3) (2014). DOI: 10.1061/(ASCE)AE.19435568.0000149. pp. 05014002, ISSN: 1076-0431.

[13] Sánchez-Beitia, S., Stresses analysis at the Altes museum of Berlin by means of the hole-drilling technique (Donostia method). Construction and Building Materials, 21(8), 1680-1687 (2007). DOI: 10.1016/j.conbuildmat.2006.05.052.

[14] Sánchez-Beitia, S., Schueremans, L. \& Van Balen, K., On-site stress measurement on the piers of the Saint Jacobs church in Leuven, Belgium. International Journal of Architectural Heritage, 3(2), 110-125 (2009). DOI: 10.1080/15583050601126137.

[15] Schajer, S.G. \& Yang, L., Residual-stress measurement in orthotropic materials using the hole-drilling method. Experimental Mechanics, 34(4), 324-333 (1994). DOI: 10.1007/BF02325147.

[16] Inter-sector round table on Wood/Euskadiko Zur Mahaia. Project Development Report on the mechanical characterization of large section radiate pine beams from the Basque Country. 